\title{
Progressive Collapse of Historical Building under Blast Load
}

\author{
Munther Mohd ${ }^{1}$, Yasin M. Fahjan² \\ ${ }^{1}$ Department of Civil Engineering, An Najah national University, Nablus, Palestine.
}

${ }^{2}$ Earthquake and Structural Engineering Department, Gebze Institute of Technology, 41400 Kocaeli, Turkey.

\begin{abstract}
The analysis of the structural failure of a historical/ heritage gothic architecture church caused by a blast load is presented in this paper. A practical approach progressive collapse of masonry structure under blast load has been developed. All the process from the discharge of the explosive to the partially destruction of the structure is presented, including the propagation of the blast wave and its interaction with the walls of the structure. The mathematical model of the church is developed in a finite element software (SAP2000), and it is subjected to simulated high explosion loads, afterward the dynamic response of the structure is evaluated in terms of maximum deflection and stresses induced. The problem analyzed corresponds to an actual heritage building that has suffered an internal Blast during the famous siege of Famagusta (Cyprus) in 1571. The paper includes comparisons with photographs of the real damage produced by the explosive charge that validates all the simulation procedure.
\end{abstract}

Keywords: dynamic response, explosive loads, finite element analysis, historical structures, stone masonry.

\section{INTRODUCTION}

Ancient structures were built using stone masonry without any consideration to their performance requirements during catastrophic events such as man-made hazards as explosions. Recent explosive attacks on major civilian buildings and places of archaeological importance all around the world have necessitated the need of research in the analysis and safety of these historical/heritage structures. These attacks have confirmed the receptiveness of heritage masonry structures under such events. The consequences of failure of stone masonry structures are severe in terms of loss of life, economic loss and moreover, heritage damage apart from the sentiments of people attached to these structures. These structures were designed and constructed when present day threat like explosions did not exist. Therefore, utmost concern is analysis of these structures and behaviour under complex loading resulting from explosion. Much research has been carried out in last year concerning the behaviour of structural elements and materials under blast loads. The experimental results about the behaviour of steel [1,2], concrete [3,4,5], and fiber reinforced [6] panels subjected to explosions can be found in the bibliography. However only few researches has been done concerning a stone masonry structures [7]. The present study is aimed to develop a practical approach progressive collapse of masonry structure under blast load, and apply it on a heritage stone masonry gothic structures subjected to explosive loads, using numerical simulation finite element method (FEM) since experimental tests in such cases is not feasible. The actual structure is a ruin called St. George of the Latins in Famagusta that has been suffered an internal blast load during the famous siage of Famagusta in 1571. As a result of the explosion, the vaulting of the south side and the roof of the great cathedral completely collapsed, however the northern side of the church and the three-sided apse were not damaged. In order to reproduce the structural collapse, the complete architectural form of the ruins was modelled, and appropriate numerical models were used for the different elements that are in the structure. Then mechanical properties of the materials were obtained from tests on parts of the actual structure.

\section{EXPLOSION AND AIR BLAST LOADING}

An explosion is defined as a large-scale, rapid and sudden release of energy. The threat for an explosion can be is defined by two equally important elements, the explosive size, or charge weight $W$, and the standoff distance $R$ between the blast source and the target. The observed characteristics of air blast waves are found to be affected by the physical properties of the explosion source. Figure 1 shows a typical blast pressure profile. At the arrival time $t A$, following the explosion, pressure at that position suddenly increases to a peak value of overpressure, Pso, over the ambient pressure, $P o$. The pressure then decays to ambient level at time $t d$, then decays further to an under pressure Pso - (creating a partial vacuum) before eventually returning to ambient conditions at time $t d+t d-$. The quantity Pso is usually referred to as the peak side-on overpressure, incident peak overpressure or merely peak overpressure [8]. 


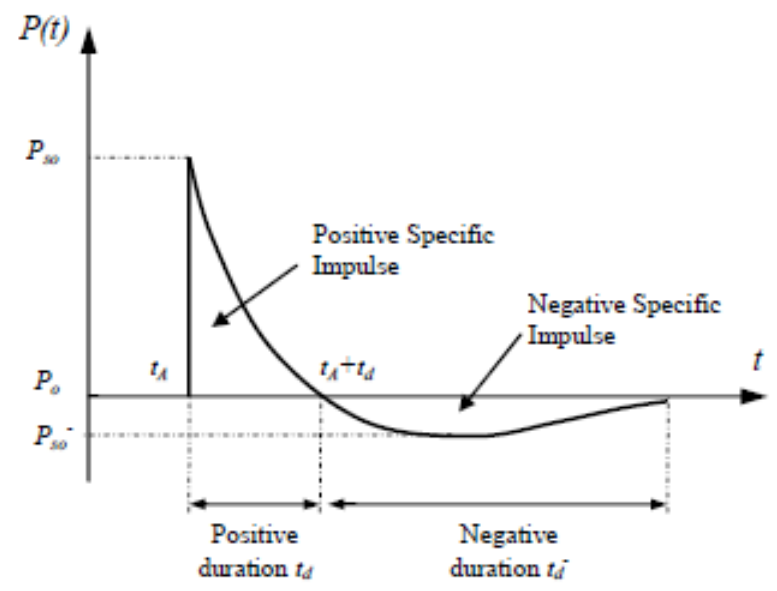

Figure 1: Blast wave pressure - Time history

Throughout the pressure-time profile, two main phases can be observed; portion above ambient is called positive phase of duration $t d$, while that below ambient is called negative phase of duration, $t d$-. The negative phase is of a longer duration and a lower intensity than the positive duration. As the stand-off distance increases, the duration of the positive-phase blast wave increases resulting in a lower-amplitude, longer-duration shock pulse. Charges situated extremely close to a target structure impose a highly impulsive, high intensity pressure load over a localized region of the structure; charges situated further away produce a lower-intensity, longer-duration uniform pressure distribution over the entire structure. Eventually, the entire structure is engulfed in the shock wave, with reflection and diffraction effects creating focusing and shadow zones in a complex pattern around the structure. During the negative phase, the weakened structure may be subjected to impact by debris that may cause additional damage.

\subsection{Prediction of blast pressure}

Blast wave parameters for conventional high explosive materials have been the focus of a number of studies during the 1950's and 1960's. Estimations of peak overpressure due to spherical blast based on scaled distance $Z=R / W 1 / 3$ were introduced by [9] as:

$$
\begin{aligned}
P_{s o} & =\frac{6.7}{Z^{3}}+1 \quad \operatorname{bar}\left(P_{\text {so }}>10 \text { bar }\right) \\
P_{s o} & =\frac{5.85}{Z^{3}}+\frac{1.455}{Z^{2}} \\
+ & \frac{0.975}{Z}-0.0191 \quad \operatorname{bar}\left(0.1 \text { bar }<P_{\text {so }}<10 \text { bar }\right)
\end{aligned}
$$

[10] introduced a relationship to calculate the maximum blast overpressure, Pso, in bars, for a high explosive charge detonates at the ground surface as:

$$
P_{s o}=6784 \frac{W}{R^{3}}+93\left(\frac{W}{R^{3}}\right)^{\frac{1}{2}}
$$

Another expression of the peak overpressure in $\mathrm{kPa}$ is introduced by [11], in which $W$ is expressed as the equivalent charge weight in kilograms of TNT, and $Z$ is the scaled distance:

$$
P_{s o}=\frac{1772}{Z^{3}}-\frac{114}{Z^{2}}+\frac{108}{Z}
$$

As the blast wave propagates through the atmosphere, the air behind the shock front is moving outward at lower velocity. The velocity of the air particles, and hence the wind pressure, depends on the peak overpressure of the blast wave. This later velocity of the air is associated with the dynamic pressure, $q(t)$. The maximum value, $q s$, say, is given by

$$
q_{s}=5 P_{s o}^{2} / 2\left(P_{s o}+7 P_{o}\right)
$$

If the blast wave encounters an obstacle perpendicular to the direction of propagation, reflection increases the overpressure to a maximum reflected pressure $\operatorname{Pr}$ as:

$$
P_{r}=2 P_{s o}\left\{\frac{7 P_{o}+4 P_{s o}}{7 P_{o}+P_{s o}}\right\}
$$

A full discussion and extensive charts for predicting blast pressures and blast durations are given by $[12,8]$. Some representative numerical values of peak reflected overpressure are given in Table 1 [13].

Table 1: Peak reflection overpressures $\mathrm{P}_{\mathrm{r}}(\mathrm{MPa})$ with different W-R combinations.

\begin{tabular}{|c|c|c|c|c|}
\hline W & $\begin{array}{c}100 \mathrm{~kg} \\
\text { TNT }\end{array}$ & $\begin{array}{c}500 \mathrm{~kg} \\
\text { TNT }\end{array}$ & $\begin{array}{c}1000 \mathrm{~kg} \\
\text { TNT }\end{array}$ & $\begin{array}{c}2000 \mathrm{~kg} \\
\text { TNT }\end{array}$ \\
\hline $1 \mathrm{~m}$ & 165.8 & 354.5 & 464.5 & 602.9 \\
\hline $2.5 \mathrm{~m}$ & 34.2 & 89.4 & 130.8 & 188.4 \\
\hline $5 \mathrm{~m}$ & 6.65 & 24.8 & 39.5 & 60.19 \\
\hline $10 \mathrm{~m}$ & 0.8 & 4.25 & 8.15 & 14.7 \\
\hline $15 \mathrm{~m}$ & 0.27 & 1.25 & 2.53 & 5.01 \\
\hline $20 \mathrm{~m}$ & 0.14 & 0.54 & 1.06 & 2.13 \\
\hline $25 \mathrm{~m}$ & 0.09 & 0.29 & 0.55 & 1.08 \\
\hline $30 \mathrm{~m}$ & 0.06 & 0.19 & 0.33 & 0.63 \\
\hline
\end{tabular}

\section{PRACTICAL APPROACH OF BLAST ANALYSIS}

The analysis of the structural collapse of a historical masonry building will be performed in two stages. The first part of the analysis consists on the simulation of the explosion itself, and the second part consists on the analysis of the effect of the blast wave generated by the explosion on the building. Only the load produced by the air blast wave will be considered in 
the analysis. The ground motion generated by the explosion will not be taken into account because the explosive is supposed to be approximately placed on the ground level.

For the first stage the blast environment will be considered as surface burst blast, by fixing the charge weight (W) and finding the stand-off distance $(\mathrm{R})$ between elements of the masonry walls and charge centre, the correlation between the scaled distances $\left(\mathrm{Z}=\mathrm{R} / \mathrm{W}^{1 / 3}\right)$ and the pressure on the stone walls will be identified. Then the blast pressure time history will be charted from [8].

After the simulation of the explosion itself, the structural behaviour of the building, the propagation of the blast wave and its interaction with the building will be analyzed. For that purpose, the analysis of blast load will be performed by nonlinear time history analysis, a direct integration time history analysis solves the entire structure at each time step is executed. This will be achieved by considering each step of the blast load and check the internal stresses of the structure, if exceeding the material capacity, the structural elements will be removed, and the cycle of the analysis will be continual. As a result of the nonlinear time history analysis the exceeded stressed elements of the model will be removed then finally a static gravity loading case will be performed to check the internal stresses in the remaining structural elements, the purpose of this gravity analysis is to decide the final building form; hence all the exceeded stressed member has been removed, ending up with the final form.

\section{STRUCTURAL MODEL}

St. George of the Latins in Famagusta (figure 2) had been studied in many papers such as $[14,15,16,17]$, but none of them intended to investigate the cause of failure considering Blast effect, in this paper a complete architectural form of the ruins was done and analyzed, to have a complete idea about the structural behavior of the architectural form of St. George of the Latins under certain blast loading conditions.

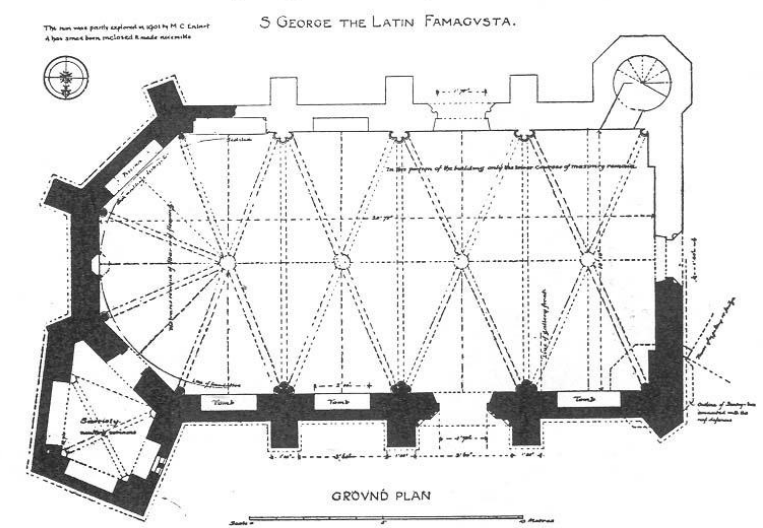

Figure 2: Perspective and Plan of the St. George of the Latins

\subsection{Historical Review}

The church of St.George of the Latins is erected just across the castle ditch on its southern side in Famagusta (figure 3).

The plan of the ancient temple can be considered in a form which consists of a nave of four bays ending in a three-sided apse, for the stability of the Gothic architecture a multicolumnar system can be seen in the form, the ribbed vaults supported in the nave by groups of three slender columns in the north and south sides, while a single column was used in the east and west corners. The church contains three doorways, one of them placed at the west end, while the other two doorways where placed on the north and south sides of the second bay of the nave.

The ancient temple of St. George of the Latins is one of the remarkable ruins due to its solid strength against to innumerable earthquakes, violent winds, and battering by artillery, but the sandstones that were very well formed for the construction of the Gothic architecture, have been corroded due to the location of the church which was close to the seashore in a country.

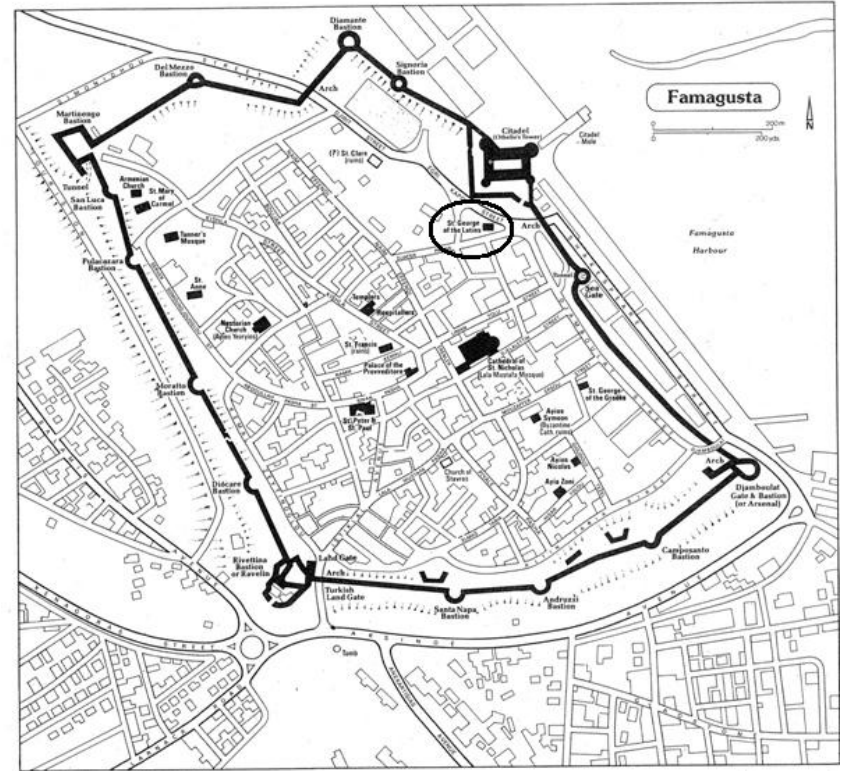

Figure 3: Map of Famagusta with St. George of the Latins location. [18] 
International Journal of Engineering Research and Technology. ISSN 0974-3154, Volume 13, Number 9 (2020), pp.2106-2114

(C) International Research Publication House. https://dx.doi.org/10.37624/IJERT/13.9.2020.2106-2114

Another great merit of this ruin can be considered as the various architectural features amongst the curious details such as the curve of the vaulting ribs, multi-columnar system, capital of a mullion, frieze at north-west corner, capitals, bracket, corbelling of the turret, crocket from doorway etc... . All these details and its ornamentations had been published by [19].

\subsection{Computational Modeling}

In the present section structural analysis of the church has been performed, the numerical analysis is based on macro modeling. The main aim of the analysis is to verify the applicability of the tools to represent the behavior of this historical masonry complexes under gravitational, and Blast loads.

General 3-D views of the church as well as the finite element model with detailed view are shown in figure 4.

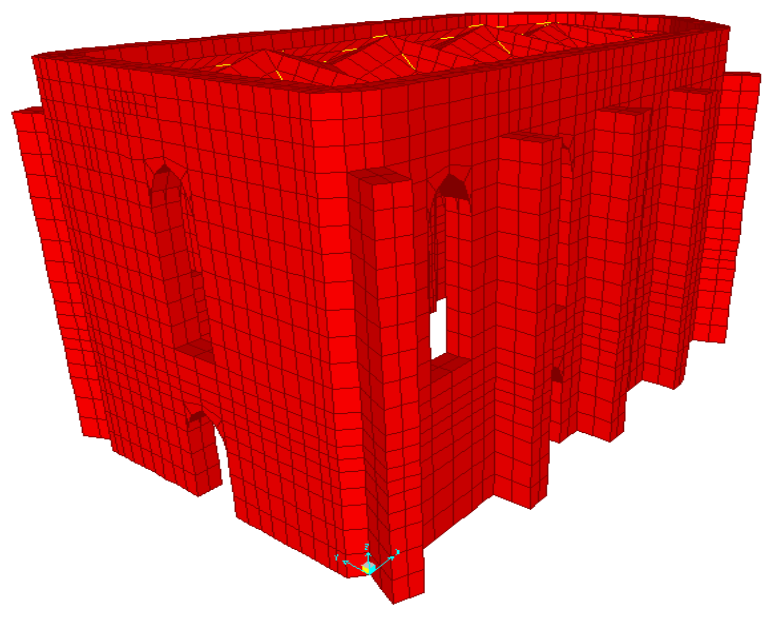

Figure 4: General 3D view of the church

In order to model the church, solid, and shell elements were used. The number of nodes needed as well as number of solids, and positions of these elements are given in Table 2.
Table 2: Element locations and numbers

\begin{tabular}{|c|c|c|}
\hline Position & $\begin{array}{c}\text { Type of } \\
\text { Element }\end{array}$ & $\begin{array}{c}\text { Number of } \\
\text { Element }\end{array}$ \\
\hline Walls and buttresses & Solid & 5632 \\
\hline Vaults & Shell & 967 \\
\hline Total number of nodes & & 10143 \\
\hline
\end{tabular}

In order to have a complete Structural modeling of the ruin, Laboratory test were previously obtained [20,21], and the properties of that material were calculated as shown in table 3.

Table 3: Elements Basic Properties

\begin{tabular}{|c|c|c|c|c|}
\hline $\begin{array}{c}\text { Element } \\
\text { Type } \\
\text { Form }\end{array}$ & $\begin{array}{l}\text { Element } \\
\text { Type } \\
\text { Modeling }\end{array}$ & $\begin{array}{c}\text { Modulus } \\
\text { of } \\
\text { Elasticity } \\
\mathrm{E}(\mathrm{x} \\
\left.10^{9} \mathrm{~N} / \mathrm{m}^{2}\right)\end{array}$ & $\begin{array}{c}\text { Poisson's } \\
\text { Ratio } \\
\text { J }\end{array}$ & $\begin{array}{c}\text { Capacity } \\
(\mathrm{MPa})\end{array}$ \\
\hline $\begin{array}{l}\text { Arches } \\
\text { (Ribs) }\end{array}$ & Frame & 10 & 0.2 & \multirow{3}{*}{$\begin{array}{c}\text { Tension } \\
(0.3) \\
\text { Comp. } \\
\text { (6) }\end{array}$} \\
\hline $\begin{array}{c}\text { Buttresses, } \\
\text { Walls }\end{array}$ & Solid & 10 & 0.2 & \\
\hline Vaults & Shell & 10 & 0.2 & \\
\hline \multicolumn{5}{|c|}{ Failure Criteria: Principle stresses } \\
\hline
\end{tabular}

\section{BLAST ANALYSIS OF THE CHURCH}

In this sample problem, an explosive device consists of TNT was assumed to be located inside the building just near the southern east façade 1 meters from inside. The blast load was assessed in application to the internal walls with its centre $1 \mathrm{~m}$ above the ground, as shown in figure 5 . This idea can be assumed as a result of information collected from the local residents' explaining that this church was used to store the explosive black powder during the war in 1571, and the collapse of the structure was due to the internal explosion of the stored powder, which was allocated just near the eastern door in between the eastern and southern walls as shown in figure 5 .

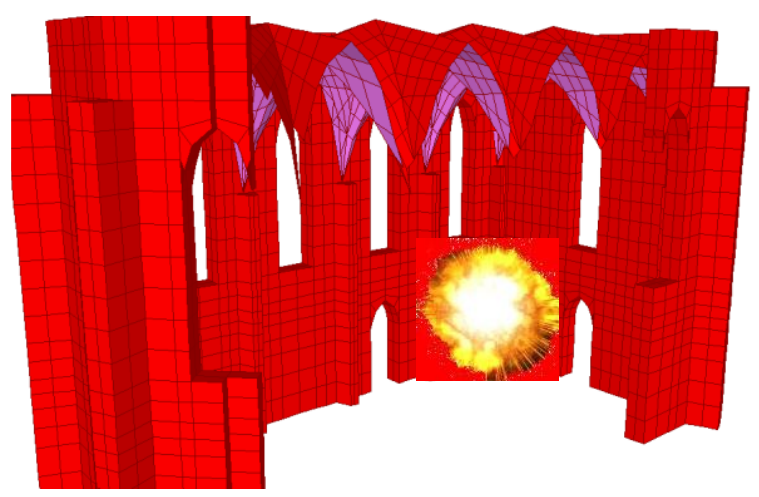

Figure 5: Blast load location 
For the purpose of realistic results and following the fact that the weight of the explosive source is not exactly known, the analysis of the structure was done assuming different explosive weight (W), considering (50 kg, $100 \mathrm{~kg}, 200 \mathrm{~kg}$, $500 \mathrm{~kg}$ ) of TNT.

\subsection{Blast Loading}

Following the procedure that has been explained in section 3, the blast environment was set as surface burst blast, by fixing the charge weight $(\mathrm{W})$ and finding the stand-off distance (R) between solid elements of the masonry walls and charge centre, the correlation between the scaled distances $\left(\mathrm{Z}=\mathrm{R} / \mathrm{W}^{1 / 3}\right)$ and the pressure on the stone walls was identified. To complete the first stage of the analysis the blast pressure time history was charted from [8] as shown in figure 6 .

\subsection{Prediction of Blast Pressure}

By assuming the charge weight (W) is equal to $50 \mathrm{~kg}$ TNT (first case) and stand-off distance ( $R$ ) to be calculated as the real distant between the explosive charge centre and the location of each solid element in the modeled structure. Then correlation between the scaled distances $\left(\mathrm{Z}=\mathrm{R} / \mathrm{W}^{1 / 3}\right)$ and the pressure on the stone walls was identified accordingly, figure 7 can show the pressure distribution on the solid elements of the structural walls. The same procedure has been repeated for all the other cases.

\subsection{Structural Analysis}

The analysis of blast load is performed by nonlinear time history analysis, a direct integration time history analysis solves the entire structure at each time step was executed. By following the results of each step of the blast load, the internal stresses of the structure was checked, the all structural elements exceeded the material capacity had been removed, and then the cycle of the analysis has been repeated. As a result of the nonlinear time history analysis the exceeded stressed elements of the model has been removed then finally a static gravity loading case has been performed to check the internal stresses in the vaulted roof shell elements after the collapse of some of the walls and the buttresses, the purpose of this gravity analysis was to decide the final building form; hence all the exceeded stressed member has been removed, ending up with the final failed form. The same procedure has been performed for all the 4 loading cases.

\section{ANALYSIS RESULTS}

Considering all the cases results, the first step results (remaining elements that has not exceeded the material capacity) of the nonlinear time history analysis can be shown in figure 8 . The failures of most of the structural elements following the $500 \mathrm{~kg} 200 \mathrm{~kg}, 100 \mathrm{~kg}$, TNT detonation are shown in Fig. 8a, 8bm 8c, respectively. The erosion of most of the buttresses and walls of the eastern southern corner after the first step is showed in Fig. 8d. Considering the real structural situation, the most appropriate and acceptable explosive weight can be considered as $50 \mathrm{~kg}$ TNT. Although the complete analysis has been done for all the different loading cases, only the complete analysis of the $50 \mathrm{~kg}$ explosive will be explained, following the situation of the existing structure.

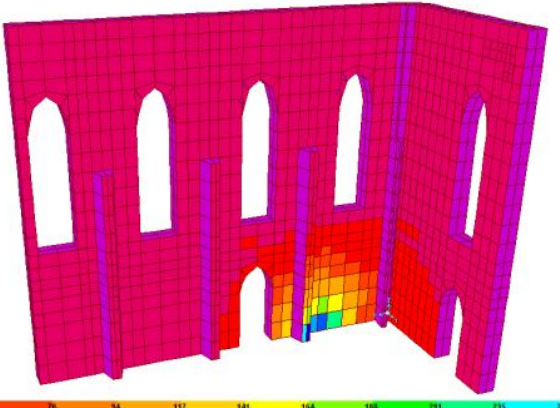

Figure 7: Distribution of blast pressure on the internal walls (50 kg TNT, at $1 \mathrm{~ms}$ Time).

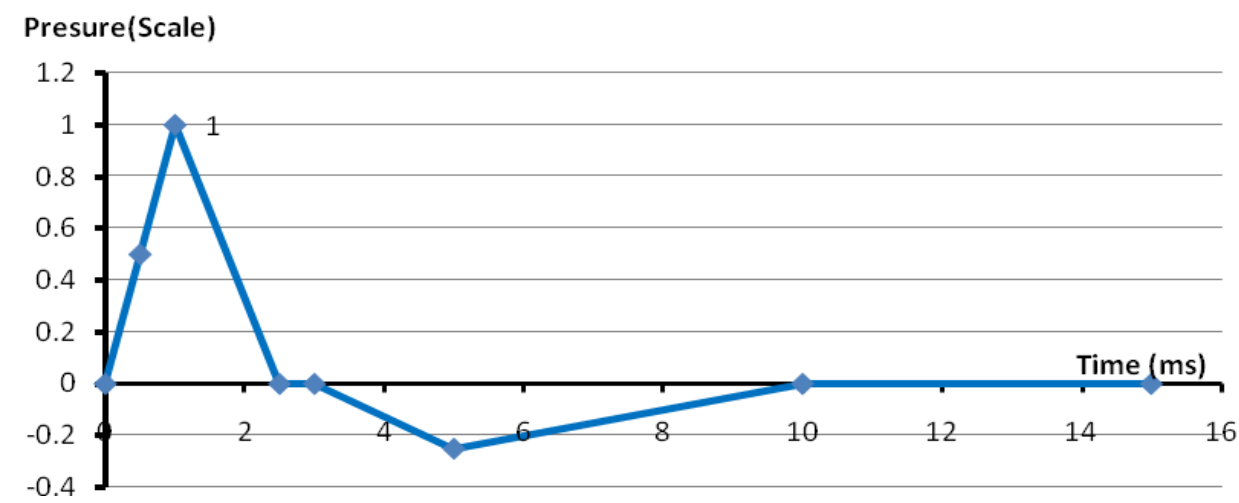

Figure 6: Average Pressure-time history variation (1 means maximum) 


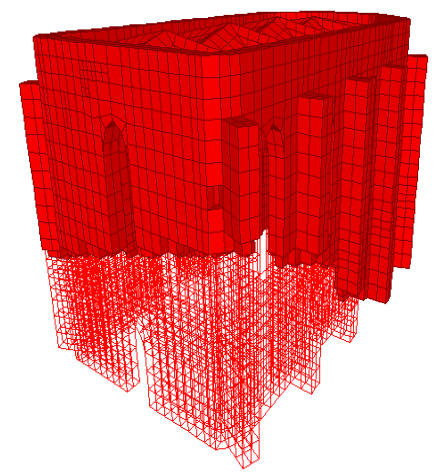

(a)

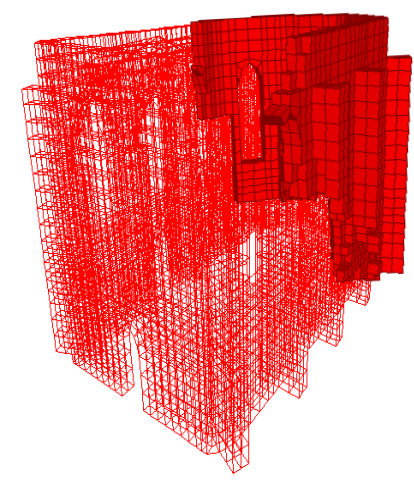

(c)

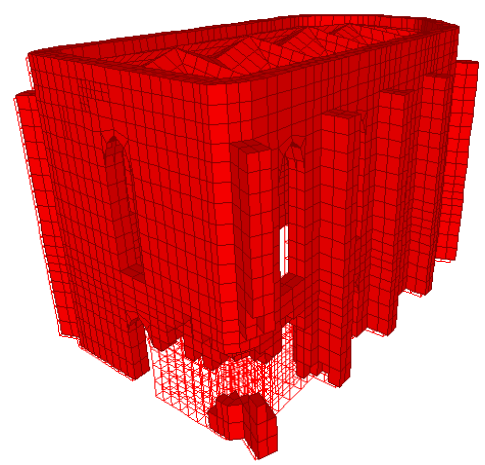

(b)

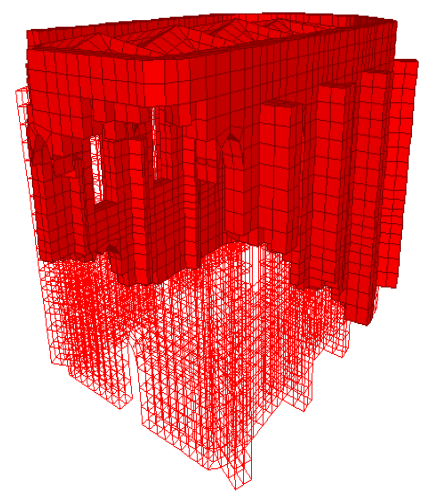

(d)

Figure 8: Evaluation of Damage (TNT) (a) $500 \mathrm{~kg}$, (b) $200 \mathrm{~kg}$, (c) $100 \mathrm{~kg}$, (d) $50 \mathrm{~kg}$.

The results obtained (deformation and stress distribution) for an explosive load of $50 \mathrm{~kg}$ of TNT located $1 \mathrm{~m}$ above the ground level, $1 \mathrm{~m}$ inside the building are shown in Fig. 9. The magnitude of the explosive load and its location were obtained in the previous sections. For the sake of visualization, only the front views of the eastern southern corner block of the building are shown. The first moments following the detonation are shown in Fig. 9a. The erosion of most of the buttresses and walls of the eastern southern corner after the first stage is showed in Fig. 9b. The failures of most of eastern southern walls, loosening of the corner block is clear in Fig. 9c. The free fall of the eastern and southern walls and the connected roof vaults can be seen in Fig. 9d. The final state of the collapsed structure can be observed in Fig. 9e (after passing nearly 10 seconds). 
International Journal of Engineering Research and Technology. ISSN 0974-3154, Volume 13, Number 9 (2020), pp.2106-2114

(C) International Research Publication House. https://dx.doi.org/10.37624/IJERT/13.9.2020.2106-2114
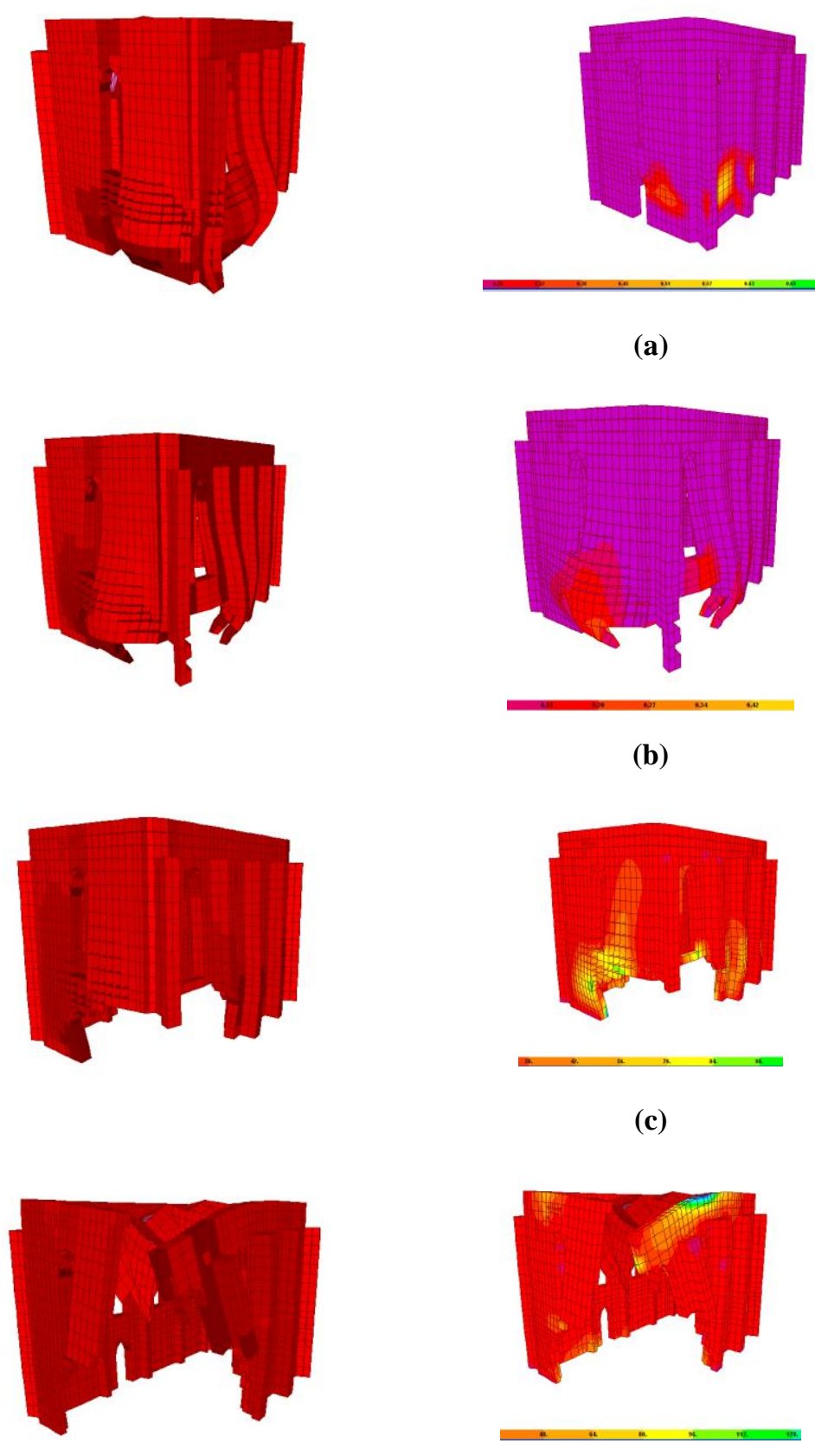

(d)
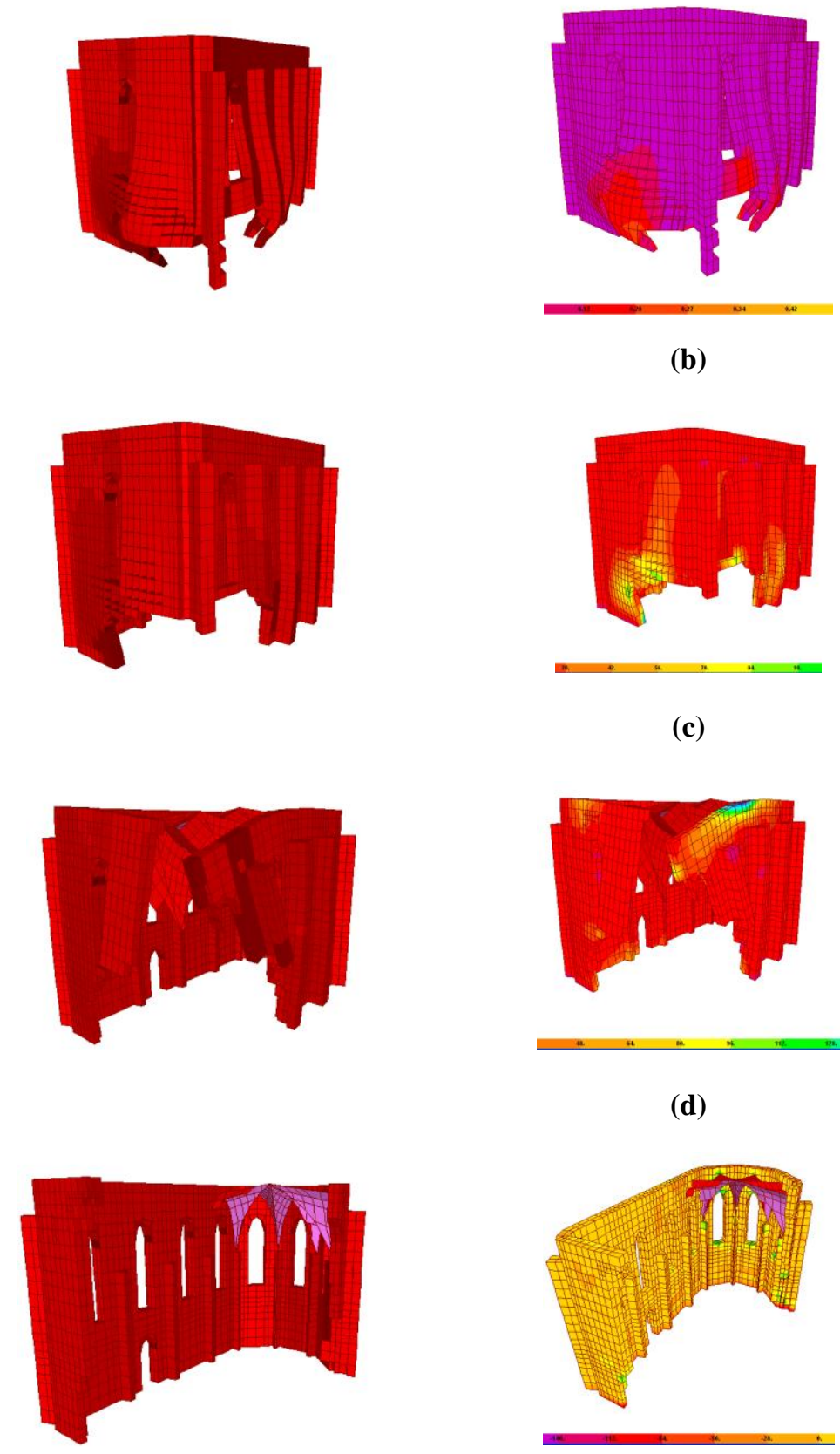

(b)

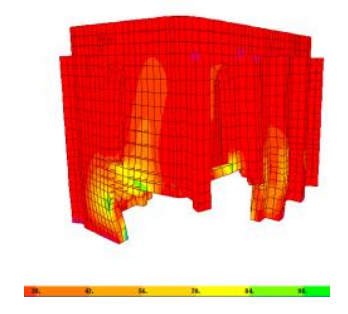

(c)

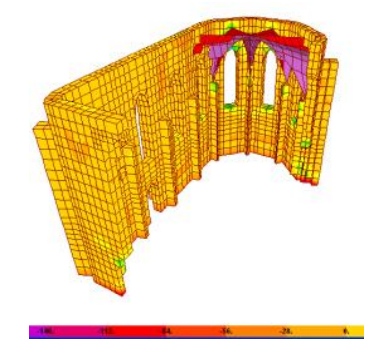

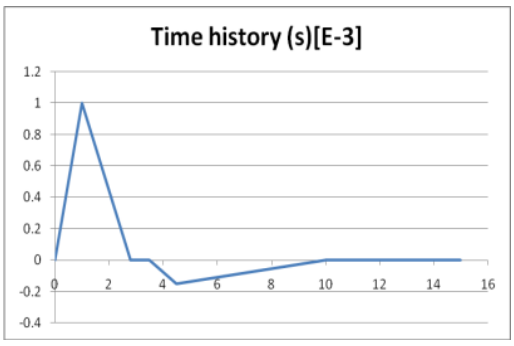

(0.5ms)

(e)

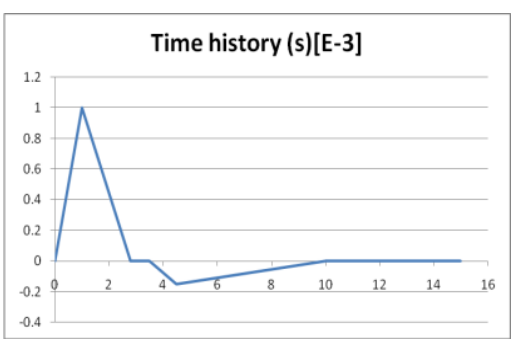

(1 ms)

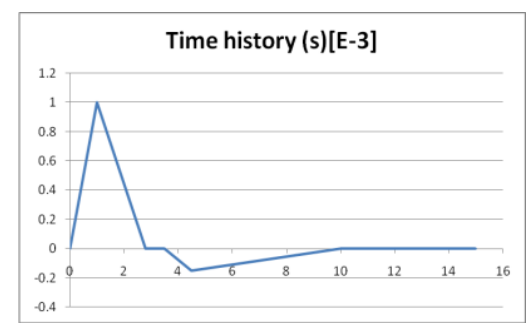

(1.8 ms)

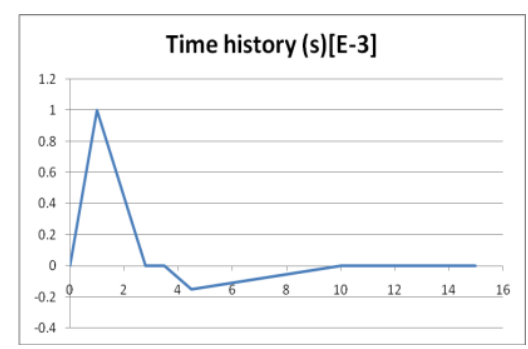

(10 ms)

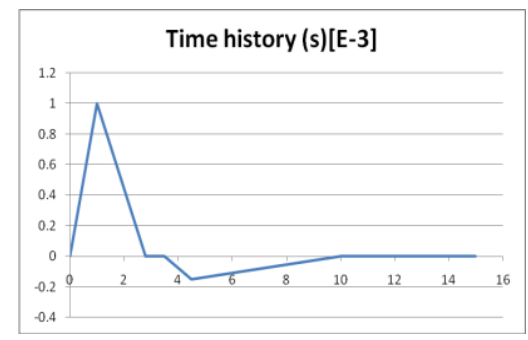

(10 s)

Figure 9: Evaluation of Damage produced by explosion, deformation and stress distribution. (a) $0.5 \mathrm{~ms}$, (b) $1 \mathrm{~ms}$, (c) $1.8 \mathrm{~ms}$, (d) $10 \mathrm{~ms}(\mathrm{e}) 10 \mathrm{~s}$. 


\subsection{Progressive Collapse mechanisms}

The structural collapse was due to a gravitational mechanism produced by the failure of most of the eastern and southern load bearing walls and buttresses of the third stage of the blast analysis. The bearing walls closer to the explosion focus failed due to the direct effect of the pressure that produced the erosion of buttresses. Southern wall lost connection in its middle point due to the existing of the door and the window over each other (tension failure), due to the tension effect
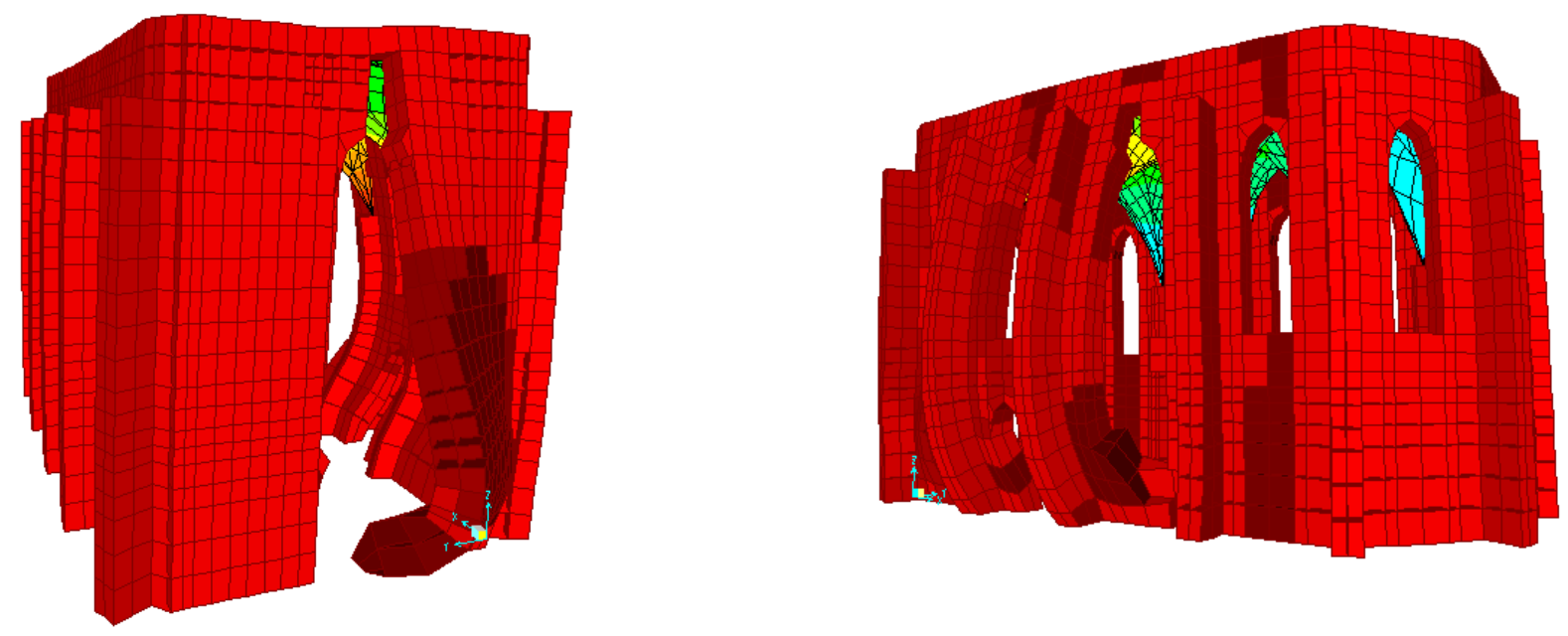

Figure 10. Collapse mechanism of the Southern and the eastern wall.

\subsection{Comparison with actual Damage}

Comparisons of the numerical simulation results with photographs of the actual existing damage structure is presented in figure 11 shows similarity between the final state imparted by the eastern wall that were pushed to the east and half of the southern wall was pushed to the south, and then failed by lack of lateral support when the pressure wave reached them (see Figure 10). The first 3 layers solids of the lower level resulted almost completely destroyed (Figure $9 \mathrm{~b}$ ) leaving without support the upper wall elements that began to fall down pulling from the western wall. The vault and the wall elements in the upper levels of the eastern and southern bearing walls have failed by a combination of tension, and shear.

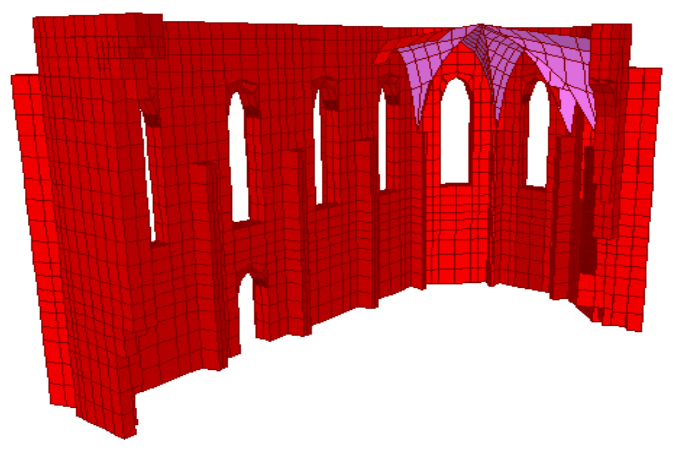

of model and the distribution of the remains in the actual building. Fig. 11 shows that the numerical simulation reproduces the fall of the vault roof that resulted hanging from the back part of the building.

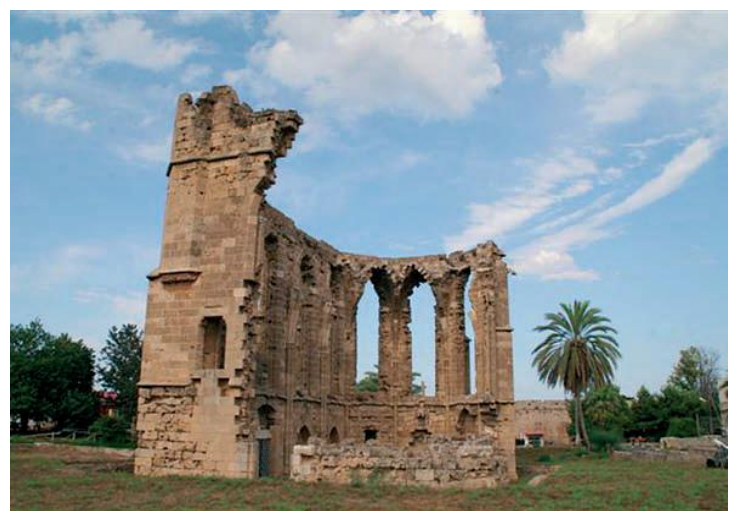

Figure 11. Comparison with actual damage. 


\section{CONCLUSION}

A practical approach progressive collapse of masonry structure under blast load has been developed. The analysis of the structural failure of a historical/ heritage gothic architecture church caused by a blast load has been studied. The actual structure is a ruin called St. George of the Latins in Famagusta that has been suffered an internal blast load during the famous siage of Famagusta in 1571. The finite element model of was generated using the available SAP2000 structural software. The analyses of the structure for both gravity as well as blast loading were completed in detail. For the purpose of realistic results and following the fact that the weight of the explosive source is not exactly known, the analysis of the structure was done assuming different explosive weight (W), considering (50 kg, $100 \mathrm{~kg}, 200 \mathrm{~kg}$, $500 \mathrm{~kg}$ ) of TNT. Referring to the real structural situation the most appropriate and acceptable explosive weight was considered as $50 \mathrm{~kg}$ TNT. By considering the gravity loading results, the structure still is very far from collapse if compare to the levels obtained for Blast analyses ; hence The result that has been obtained from the analysis has clarified that the acceptable reason of collapse, was due to internal blast.

\section{REFERENCES}

[1] Jacinto A, Ambrosini RD, Danesi RF. Experimental and computational analysis of plates under air blast loading. Int J Impact Eng 2001;25(10):927-47.

[2] Jacinto A, Ambrosini RD, Danesi RF. Dynamic response of plates subjected to blast loading. Proc Inst Civ Eng Struct Build, 2002;152(3):269-76.

[3] Yi P. Explosionseinwirkungen auf Stahlbetonplatten. Zur Erlangung des akademischen Grades eines DoktorIngenieurs der Fakulta "t fu“ $r$ Bauingenieur- und Vermessungswessen der Universita“ $t$ Fridericiana $z u$ Karlsruhe (TH), 1991.

[4] Mays GC, Hetherington JG, Rose TA. Response to blast loading of concrete wall panels with openings. ASCE J Struct Eng 1999;125(12):1448-50.

[5] Luccioni B M., Ambrosin R D, Danesi R F, Analysis of building collapse under blast loads. Engineering Structures 26, 2004 63-71.

[6] Lok TS, Xiao JR. Steel-fibre-reinforced concrete panels exposed to air blast loading. Proc Inst Civ Eng Struct Build 1999;134:319-31.

[7] Goel M D, Matsagar V A, Benipal G S, Gupta A K. Dynamic response of shell structures subjected to explosive loads. Proceedings of the IMPLAST 2010 Conference, october 12-14 2010 providence. Rhode Island, USA.

[8] TM 5-1300. The Design of Structures to Resist the Effects of Accidental Explosions, Technical Manual. US Department of the Army, Navy, and Air Force, Washington DC, 1990.

[9] Brode, H.L.. Numerical solution of spherical blast waves. Journal of Applied Physics, American Institute of Physics, Ney York, 1955.

[10] Newmark, N.M. and Hansen., R.J., .Design of blast resistant structures. Shock and Vibration Handbook, Vol. 3, Eds. Harris and Crede. McGraw-Hill, New York, USA. 1961.

[11] Mills, C.A., . The design of concrete structure to resist explosions and weapon effects. Proceedings of the 1st Int. Conference on concrete for hazard protections, Edinburgh,UK, pp. 61-73, 1987.

[12] Mays GC, Smith PD. Blast Effects on Buildings. Thomas Telford Services Ltd, 1 Heron Quay, London E14 4JD, 1995.

[13] T. Ngo, P. Mendis, A. Gupta \& J. Ramsay. Blast Loading and Blast Effects on Structure. The University of Melbourne, Australia, 2007.

[14] Lourenço, P. B., \& Ramos, L. F. Preliminary Report on the Inspection on Three Famagusta Churches. Guimarães: Universidade de Minho, 2008.

[15] Walsh, M. J. (2007). Famagusta An appeal for International Cooperation. Famagusta: Eastern Mediterranean University. 2007.

[16] Trujillo, A. "Stability analysis of Famagusta Churches: Saint George of the Latins". MSc- Dissertation, University of Minho, 2009. Guimarães July 2009.

[17] Lourenço, P.B., Ramos, L. F., Trujillo, A. In situ investigation and stability analysis of Famagusta Churche"s, 8th International Masonry Conference 2010 in Dresden

[18] Enlart, C. Gothic Art and the Renaissance in Cyprus. (S. D. Hunt, Ed.) Trigraph Ltd. 1913

[19] Enlart, C. Gothic Art and the Renaissance in Cyprus. Trigraph London, pp. 258-262. 1987

[20] M. Under, M. Mohd . A study on the architectural identification and the art of the stress distribution of St. George of the Latins in Famagusta. Gazimagusa Symposium pp.415-423, 2004

[21] M. Under, M. Mohd . A study on the backfill role on the stability of St. George of the Latins in Famagusta (Gothic Form). $3^{\text {rd }}$ FAE International Symposium Creating the Future pp.69-73, 2004 